\title{
Personality traits in patients with refractory versus non-refractory epilepsy
}

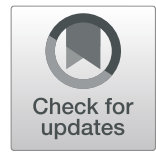

\author{
Khaled A. M. Elbeh, Yasser M. Elserogy, Menna F. Hamid and Romany H. Gabra* (D)
}

\begin{abstract}
Background: Epilepsy has significant effects on the behavior of most people who suffer it. In some cases, the seizure activity itself is manifested as a brief change in behavior that might appear unusual to the casual observer. Evidence also suggests that epilepsy can affect behavior when seizures are not occurring. Descriptions of inter-ictal behavior in people with epilepsy have a long and controversial history. The study aims to assess the personality disorders among epileptic patients and impact of the severity of epilepsy on personality traits. Methods: This study is conducted upon 90 patients presented at outpatient clinic of epilepsy in Assiut University Hospital diagnosed as having epilepsy versus 40 cross-matched healthy controls. Patient group were classified into two groups (refractory versus controlled groups). All patients and control were subjected to (1) detailed medical interview. (2) Assessment of intelligence using The Arabic Version of Wechsler Adult Intelligence Scale. (3) Conventional EEG study. (4) The Arabic Version of The Structured interview for the five-factor model of personality.
\end{abstract}

Results: A relationship was found between personality traits and the severity of epilepsy. When patients have more severe epilepsy, they often have a high seizure frequency, they use more antiepileptic medications. It is likely that in those patients the need for control is usually high (because seizures mean a loss of control). Regarding the fivefactor model of personality which we used to assess the personality traits of our selected studied samples, we found that the five main domains of the scale which are neuroticism, extraversion, openness to experience, agreeableness and conscientiousness differ markedly between the two groups of our patients. We found neuroticism was markedly increased at the refractory epileptic patients than the controlled epileptic ones, while extraversion, openness to experience, agreeableness, and conscientiousness increased at the controlled epileptic patients than the refractory epileptic ones.

Conclusion: Patients with epilepsy have raised scores for several personality traits also those personality traits are different in patients with refractory and controlled epilepsy. Also, those personality traits are different compared with a control group from the general population.

Keywords: Refractory epilepsy, Personality traits

\section{Background}

In the last century, many psychiatrists have discussed what is called "the epileptic personality," which is an inter-ictal syndrome characterized by explosive impulsivity, talkativeness or affective viscosity, and egocentricity (increased concern about the self). It is postulated that this syndrome may be the result of underlying neurologic brain deficit, while others

\footnotetext{
* Correspondence: romanyhosny@med.aun.edu.eg

Department of Neurology and Psychiatry, Faculty of Medicine, Assiut University, PO Box 71515, Assiut, Egypt
}

\section{Springer Open}

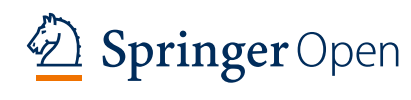

refer that these personality traits may represent as a distinct type of epilepsy itself. Recently, it was felt that intensive psychoanalytic therapy was the most appropriate treatment for this condition [1].

Perspectives changed after that as it considered patients with epilepsy were consummately typical, and keeping in mind that some may experience changes of identity auxiliary to head injuries, to the long duration of treatment with anti-convulsant, or to the outcomes of psychosocial stigma due to their fits. This "era of

(c) The Author(s). 2021 Open Access This article is licensed under a Creative Commons Attribution 4.0 International License, which permits use, sharing, adaptation, distribution and reproduction in any medium or format, as long as you give appropriate credit to the original author(s) and the source, provide a link to the Creative Commons licence, and indicate if changes were made. The images or other third party material in this article are included in the article's Creative Commons licence, unless indicated otherwise in a credit line to the material. If material is not included in the article's Creative Commons licence and your intended use is not permitted by statutory regulation or exceeds the permitted use, you will need to obtain permission directly from the copyright holder. To view a copy of this licence, visit http://creativecommons.org/licenses/by/4.0/. 
normality" was strongly suggested by Lennox (1944), and is still a valid view of many research today [2].

Another recent view is what is called "period of epileptic character," it describes that not all patients with epilepsy are liable to undergo personality changes, but it is those with chronic temporal lobe abnormality and limbic epilepsy, who are most susceptible. This "period of psychomotor changes" was most described by Gibbs and Stamps (1958); thus, "the patient's emotional reactions to his seizures, to his family, and the social situation are less important determinants of psychiatric disorder than the site and type of the epileptic discharge" [3].

The association between epilepsy and personality changes has been a focus of interest between psychiatrist and neurologists. A great deal of work has been done whether to clarify the existence of such personality changes or not, and if present the causes of such changes. Arguments arise about whether any of these personality changes were linked with the biology of the epilepsy, especially those associated with temporal lobe lesions or just they were secondary to other factors described before. Several advances in the neurosciences revealed the important role of the frontal lobes in regulating behavior, and frontal lobe syndromes, especially personality disorders, were described in animals and humans [4].

The study aims to examine personality traits among epileptic patients versus general population and its correlation with severity of epilepsy.

\section{Methods}

The current study is a descriptive case control and was conducted upon 90 patients who were previously diagnosed as epilepsies according to definition of epilepsy and were presented at outpatient clinic of epilepsy in Assiut University Hospital [5].

The patient's group: divided into two groups:

Group 1: patients with refractory epilepsy according to definition of the International League Against Epilepsy (ILAE). (The International League Against Epilepsy proposed a definition of drug-resistant epilepsy as a failure of adequate trials of two tolerated and appropriately chosen and used AED schedules) [6].

Group 2: patients with controlled epilepsy (having seizures that do not impact day to day life/significant reduction in seizures/only having auras/only having seizures in bed, at night) [7].

Patients were recruited randomly from the outpatient epilepsy clinic of the neurology and psychiatry of Assiut University Hospital, after acceptance to participate in the study.

The control group: 40 healthy adult subjects volunteered to participate in the study were from general population and matched with the patient group for age, sex, and socioeconomic state without any intracranial complaints.

Inclusion criteria:

1. Patients previously diagnosed epileptic from the outpatient clinic of Assiut University Hospital.

2. Patients with refractory epilepsy according to definition of ILAE [6].

3. Age group from 18 to 60 (excluding extremes of ages to avoid affection of personality traits with extremes of age).

4. Sex: both sexes are included in the study.

5. I.Q. more than or equal 80 .

Exclusion criteria:

1. Patients with other systemic diseases.

2. Refusal to participate in the study.

3. Patient with seizures during the last $48 \mathrm{~h}$ prior to the assessment.

\section{Study design}

The studied samples will be subjected to the following after a written informed consent was obtained from each of them:

1) Detailed interview including detailed personal, family, medical, perinatal, and past records as well as a detailed history of present illness including onset, course, symptoms, past medication, duration of illness, duration of therapy, seizure frequency, and degree of improvement

2) Assessment of intelligence using The Arabic Version of Wechsler Adult Intelligence

Scale $\{$ WAIS $\}$ :[8] (to exclude mental retardation and its affection on personality traits)

3) Conventional EEG study: conventional wakefulness 8-channels EEG was done using Nihon Kohden machine model (4217). Monopolar, bipolar, and double distance montages were done with application of hyperventilation and photic stimulation for each patient. EEG tracings were analyzed carefully as regards the background activity and presence of any epileptogenic activity. The EEG findings were described as normal and abnormal and the abnormalities were classified according to Elwan et al. 1973 [9] into borderline, mildly abnormal, moderately abnormal, and markedly abnormal as follows:

a- Borderline: 
Diffuse low voltage fast background or minimal bitemporal theta activity especially during hyperventilation, with no side asymmetry.

b- Mildly abnormal:

Only one abnormality of the following either:

-Diffuse slowing (theta) activity (4-7 c/s) or

-Focal slow waves or

-Asymmetry of the background $\breve{a}$-activity (in frequency or amplitude to > $50 \%$ or

-Paroxysmal epileptiform activity recorded $<5$ times.

c- Moderately abnormal:

More than one abnormality in the form of the following:

-Disorganization or asymmetry of the background.

-Paroxysmal epileptiform activities recurring (5-10) times.

d- Markedly abnormal:

-Paroxysmal epileptiform activities recurring $>10$ times with or without one or more than one abnormality of the previously described abnormalities.

4) The Arabic version of the structured interview for the five-factor model of personality (SIFFM) [10]:

The big five personality traits, also known as the five-factor model (FFM), is a model based on common language descriptors of personality, its theory suggests five broad dimensions commonly used to describe the human personality and psyche $[11,12]$. The five factors have been defined as openness to experience, conscientiousness, extraversion, agreeableness, and neuroticism often represented by the acronyms OCEAN or CANOE [13].

\section{Ethical considerations}

The protocol and study design of this thesis was approved by local ethical committee in the Faculty of Medicine, Assiut University. An informed consent was obtained and signed from the subjects and or their 1stdegree relatives to participate in the study.

\section{Statistical analysis}

Categorical variables were described by number and percent $(n, \%)$, whereas continuous variables were described by mean and standard deviation (mean, SD). Chi-square test and Fisher's exact test were used to compare categorical variables, while $t$ test and analysis of variance (ANOVA) were used to compare continuous quantitative variables of parametric data. Pearson correlation coefficients were used to assess the correlation between continuous variables. A two-tailed test was considered significant when $P$ was 0.05 and highly significant when $P$ was 0.01 . All analyses were performed using the IBM SPSS version 20.0 software.

\section{Result}

Epilepsy has significant effects on the behavior of most people who have it. In some cases, the seizure activity itself is manifested as a brief change or interruption in behavior that might appear unusual to the casual observer. Evidence also suggests that epilepsy can affect behavior when seizures are not occurring.

This study was conducted upon 90 patients presented at outpatients' clinic of epilepsy in the Assiut University Hospital previously diagnosed as epilepsies (means having seizures either focal or generalized with its different types of absence seizures/tonic-clonic/atonic/clonic /tonic/myoclonic) [14].

According to definition of epilepsy [5], the patients were divided into two groups: patients with refractory epilepsy according to definition of the international league against epilepsy (ILAE) [6] and patients with controlled epilepsy. Along with control group including 40 healthy adult subjects volunteered to participate in the study were from general population and matched with the patient group for age, sex, and socioeconomic state without any intracranial complaints.

The mean age in the refractory epileptic patients was 36.87 with $\mathrm{SD} \pm 8.49$, in controlled epileptic patients were 38.96 with $\mathrm{SD} \pm 13.11$ and in control cases were 36.2 with $\mathrm{SD} \pm 12.18$. The patient group consisted of 90 cases (46.67\% males and 53.3\% females), while control group consisted of 40 volunteers $(57.5 \%$ males and $42.5 \%$ females).

Regarding education, $75.56 \%$ of the patient group were illiterate, $5.56 \%$ of the patients can read and write, and $18.89 \%$ of the patients were primary educated. While control group had $82.5 \%$ illiterate, $5 \%$ can read and write, and $12.5 \%$ had primary education.

Regarding marital status in patients group, 28.89\% were single, $62.22 \%$ were married, $5.56 \%$ were divorced, and $3.33 \%$ were widows. While in control group, 30\% were single, $65 \%$ were married, and $5 \%$ were widows.

Regarding occupation, $67.78 \%$ of the patient group were not working and $32.22 \%$ were manual workers. While in control group, $42.5 \%$ were not working and $57.5 \%$ were manual workers (Table 1 ).

Table 2 shows the age at onset of epilepsy among the patient group, duration of illness in years, duration of therapy in years, and seizure frequency per year which showed higher mean and SD at refractory epileptic patients $(36.36 \pm 32.88)$ than at controlled epileptic 
Table 1 Sociodemographic data among the studied sample

\begin{tabular}{|c|c|c|c|c|c|c|c|}
\hline & Refractory e & psy & Unrefractory $\epsilon$ & epsy & Total & Control peo & \\
\hline & No. & $\%$ & No. & $\%$ & & No. & $\%$ \\
\hline Age (mean $\pm S D)$ & $36.87 \pm 8.49$ & & $38.96 \pm 13.11$ & & & $36.2 \pm 12.18$ & \\
\hline \multicolumn{8}{|l|}{ Gender } \\
\hline Male & 26 & 57.8 & 16 & 35.6 & $42(46.67 \%)$ & 23 & 57.5 \\
\hline Female & 19 & 42.2 & 29 & 64.4 & $48(53.33 \%)$ & 17 & 42.5 \\
\hline \multicolumn{8}{|l|}{ Education } \\
\hline Illiterate & 35 & 77.8 & 33 & 73.3 & $68(75.56 \%)$ & 33 & 82.5 \\
\hline Read and write & 5 & 11.1 & 0 & 0 & $5(5.56 \%)$ & 2 & 5 \\
\hline primary education & 5 & 11.1 & 12 & 26.7 & $17(18.89 \%)$ & 5 & 12.5 \\
\hline \multicolumn{8}{|l|}{ Marital status } \\
\hline Single & 15 & 33.3 & 11 & 24.4 & $26(28.89 \%)$ & 12 & 30 \\
\hline Married & 24 & 53.3 & 32 & 71.1 & $56(62.22 \%)$ & 26 & 65 \\
\hline Divorced & 5 & 11.1 & 0 & 0 & $5(5.56 \%)$ & & \\
\hline Widow & 1 & 2.2 & 2 & 4.4 & $3(3.33 \%)$ & 2 & 5 \\
\hline \multicolumn{8}{|l|}{ Occupation } \\
\hline Not working & 26 & 57.8 & 35 & 77.8 & $61(67.78 \%)$ & 17 & 42.5 \\
\hline Manual worker & 19 & 42.2 & 10 & 22.2 & $29(32.22 \%)$ & 23 & 57.5 \\
\hline
\end{tabular}

patients $(10.16 \pm 5.29)$ with a highly significant $p$ value $<$ 0.001 . It also shows medications of the epileptic patients stating that $2.2 \%$ of refractory epileptic patients were on monotherapy, while $88.9 \%$ controlled epileptic patients on monotherapy and $97.8 \%$ of refractory epileptic patients were on polytherapy, while $11.1 \%$ of controlled epileptic patients on polytherapy with a highly significant $p$ value $<0.001$.

Regarding EEG, for mild changes, $53.3 \%$ were of refractory epileptic patients and $84.4 \%$ were of controlled refractory epileptic patients; for moderate changes, $22.2 \%$ were of refractory epileptic patients and $15.6 \%$ of controlled epileptic patients; as for severe changes,
$24.4 \%$ were only of refractory epileptic patients with a highly significant difference $(p$ value $<0.001)$ stating that EEG changes were higher at refractory epileptic ones.

Table 3 shows the comparison of IQ among the studied samples shows that only performance IQ scores were significantly lower in patients with refractory epilepsy than the controlled epileptic patients and the control group.

Table 4 shows comparison between the studied groups regarding the five-factor model:

a- According to neuroticism: in patients of refractory epilepsy, the mean value was 25.51 with $\mathrm{SD} \pm 7.72$,

Table 2 Clinical and medications variables among the studied samples

\begin{tabular}{llll}
\hline & $\begin{array}{l}\text { Refractory epilepsy } \\
\text { Mean } \pm \text { SD }\end{array}$ & $\begin{array}{l}\text { Unrefractory epilepsy } \\
\text { Mean } \pm \text { SD }\end{array}$ & $p$ value \\
\hline Age at onset & $17.78 \pm 8.33$ & $20.89 \pm 8.11$ & 0.076 \\
Duration of illness (years) & $19.09 \pm 6.83$ & $18.07 \pm 9.52$ & 0.56 \\
Duration of therapy (years) & $18.38 \pm 6.85$ & $17.27 \pm 9.39$ & 0.523 \\
Seizure frequency (per year) & $36.36 \pm 32.88$ & $10.16 \pm 5.29$ & $<0.001^{* *}$ \\
Medications & & & $<0.001^{* *}$ \\
$\quad$ Monotherapy & $1(2.2 \%)$ & $40(88.9 \%)$ & $5(11.1 \%)$ \\
$\quad$ Polytherapy & $44(97.8 \%)$ & & $<0.001^{* *}$ \\
EEG & & $38(84.4 \%)$ & $7(15.6 \%)$ \\
$\quad$ Mild & $24(53.3 \%)$ & $0(0 \%)$ \\
$\quad 10(22.2 \%)$ & $11(24.4 \%)$ & \\
\hline
\end{tabular}


Table 3 Comparison between the studied sample group regarding intelligence quotient

\begin{tabular}{lllll}
\hline & $\begin{array}{l}\text { Refractory epilepsy } \\
\text { Mean } \pm \text { SD }\end{array}$ & $\begin{array}{l}\text { Unrefractory epilepsy } \\
\text { Mean } \pm \text { SD }\end{array}$ & $\begin{array}{l}\text { Control people } \\
\text { Mean } \pm \text { SD }\end{array}$ \\
\hline Verbal & $80.89 \pm 4.39$ & $80.67 \pm 4.94$ & $80.95 \pm 4.97$ & 0.958 \\
Performance & $90.16 \pm 4.4$ & $92.38 \pm 4.12$ & $91.6 \pm 4.3$ & $0.047^{*}$ \\
Intelligence quotient & $82.96 \pm 3$ & $83.64 \pm 3.26$ & $83.5 \pm 3.41$ & 0.568 \\
Deterioration index & $8.28 \pm 7.09$ & $8.33 \pm 9.55$ & $8.16 \pm 8.78$ & 0.996 \\
\hline
\end{tabular}

while in patients with controlled epilepsy, the mean value was 22.02 with $\mathrm{SD} \pm 8.92$, and in control cases, the mean value was 17.93 with $\mathrm{SD} \pm 7.99$ with high statistical significance.

b- According to extraversion: in patients of refractory epilepsy, the mean value was 18.07 with $\mathrm{SD} \pm 7.31$, while in patients with controlled epilepsy, the mean value was 20.02 with $\mathrm{SD} \pm 8.77$, and in control cases, the mean value was 22.28 with $\mathrm{SD} \pm 8.77$, and in control cases, the mean value was 22.28 with $\mathrm{SD} \pm 9.98$ with no significant statistical difference.

c- According to openness to experience: in patients with refractory epilepsy, the mean value was 7 with $\mathrm{SD} \pm 4.54$; while in patients with controlled epilepsy, the mean value was 11.07 with $\mathrm{SD} \pm 9.74$, and in control cases, the mean value was 10.1 with $\mathrm{SD} \pm 8.81$ with statistical significance.

d- According to agreeableness: in patients with refractory epilepsy, the mean value was 25.64 with $\mathrm{SD} \pm 5.25$; while in patients with controlled epilepsy, the mean value was 27.78 with $\mathrm{SD} \pm 6.48$, and in control cases, the mean value was 25.68 with $\mathrm{SD} \pm 7.65$ with no significant statistical difference.

e- According to conscientiousness: in patients with refractory epilepsy, the mean value was 12.8 with $\mathrm{SD} \pm 6.02$; while in patients with controlled epilepsy, the mean value was 16.8 with $\mathrm{SD} \pm 6.79$, and in control cases, the mean value was 13.85 with $\mathrm{SD} \pm 5.03$ with high statistical significance (Fig. 1).

\section{Discussion}

The relationship between epilepsy and personality disorders is not often the subject of many scientific investigations. Much research concentrates on psychiatric disorders, such as psychotic disorders, anxiety disorders, and mood disorders, whereas personality disorders are less likely studied in epilepsy.

This study was conducted upon 90 epileptic patients presented at outpatient clinic of epilepsy in Assiut University Hospital along with 40 healthy adult subjects volunteered to participate in the study.

In this study, epilepsy was more common in females (48 (53.33\%)) than in males (42 (46.67\%)); similar data were obtained from Tang et al. (2012) [15], and in his study of anxiety, prevalence in epileptic patients as they found that $52.6 \%$ of them were females and $47.4 \%$ were males.

Regarding the five-factor model of personality, in the current study, we found that neuroticism was highest at patients with refractory epilepsy with a mean of 25.51 and SD \pm 7.72 than the mean of the controlled epileptic patients 22.02 and $\mathrm{SD} \pm 8.92$, while lowest at control people 17.93 and $\mathrm{SD} \pm 7.99$, with a highly significant statistical difference.

For extraversion, it was lowest at the refractory epileptic patients with a mean of 25.51 and $\mathrm{SD} \pm 7.72$; while in controlled epileptic patients, the mean was 20.02 and SD \pm 8.77 , and highest in the control group with a mean of 22.28 and $\mathrm{SD} \pm 9.98$ without significant statistical difference.

For openness to experience, it was lowest at refractory epileptic patients with a mean of 7 and $\mathrm{SD} \pm 4.54$, and higher in control people with a mean of 10.1 and SD \pm 8.81, while highest in controlled epileptic patients with a mean of 11.07 and $S D \pm 9.74$ with a significant statistical difference.

For agreeableness, it was lowest at refractory epileptic patients with a mean of 25.64 and $\mathrm{SD} \pm 5.25$, higher in control group 25.68 and $\mathrm{SD} \pm 7.65$ and highest in controlled epileptic patients 27.78 and $\mathrm{SD} \pm 6.48$, without

Table 4 Comparison between the studied sample groups regarding five-factor model

\begin{tabular}{lllll}
\hline & (A) Refractory epilepsy & (B) Unrefractory epilepsy & (C) Control people & $p$ value \\
& Mean \pm SD & Mean \pm SD & Mean SD & $<0.001^{* *}$ \\
\hline Neuroticism & $25.51 \pm 7.72$ & $22.02 \pm 8.92$ & $17.93 \pm 7.99$ & 0.088 \\
Extraversion & $18.07 \pm 7.31$ & $20.02 \pm 8.77$ & $22.28 \pm 9.98$ & $0.046^{*}$ \\
Openness to experience & $7 \pm 4.54$ & $11.07 \pm 9.74$ & $10.1 \pm 8.81$ & 0.212 \\
Agreeableness & $25.64 \pm 5.25$ & $27.78 \pm 6.48$ & $25.68 \pm 7.65$ & $0.006^{* *}$ \\
Conscientiousness & $12.8 \pm 6.02$ & $16.8 \pm 6.79$ & $13.85 \pm 5.03$ & 0 \\
\hline
\end{tabular}




\section{Factor}

\section{$\square$ A) Refractory Epilepsy) $\square$ B) Un Refractory Epilepsy) $\square$ C) Control People)}

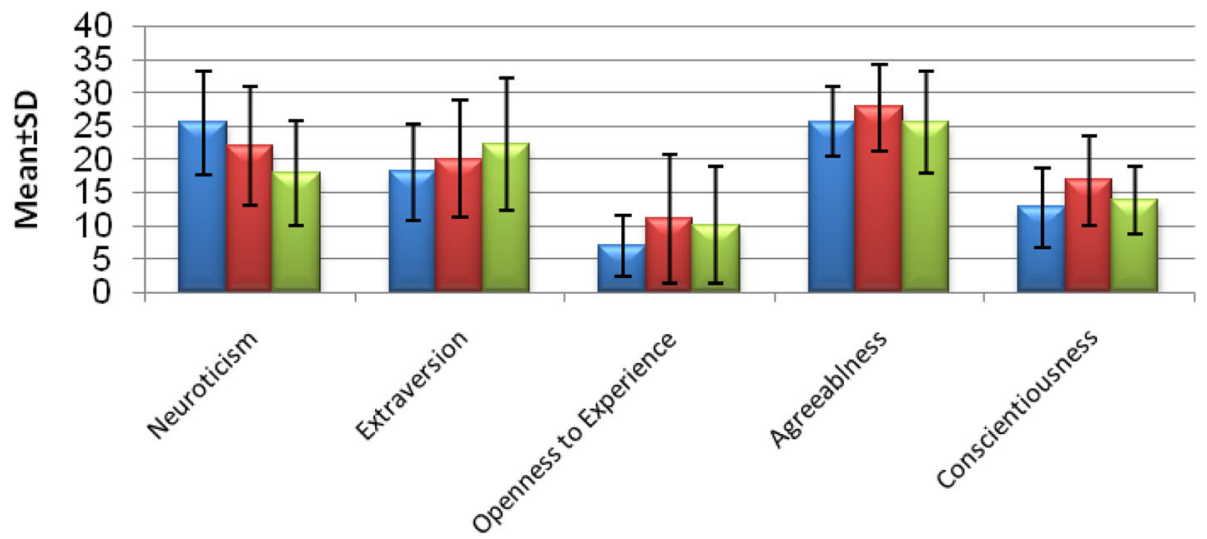

Fig. 1 Comparison between the studied sample groups regarding five-factor model

significant statistical differences. For conscientiousness, it was lowest at refractory epileptic patients with a mean of 12.8 and $\mathrm{SD} \pm 6.02$, higher in control people 13.85 and $\mathrm{SD} \pm 5.03$, and highest in controlled epileptic patients 16.8 and $\mathrm{SD} \pm 6.79$, with a highly significant statistical difference.

This was in agreement with Swinkels et al. (2004) [16] who stated in his study that the patients with epilepsy exhibit more personality disorder traits compared with a control group from the general population. Also, he agreed with us that he found a relationship that exists between personality disorders traits and the severity of epilepsy. When patients have more severe epilepsy, they often have a high seizure frequency, and they use more antiepileptic medications.

Also, Swinkels et al. (2003) have a similar data showing that, compared with the control group, patients with epilepsy had higher dimensional scores for several Diagnostic and Statistical Manual of Mental Disorders of personality disorders. Associations were found between PD traits and age at onset of epilepsy, duration of epilepsy and seizure frequency [17].

It is likely that in those patients, the need for control is usually high (because seizures mean a loss of control). Therefore, they are probably more prone to develop a behavior pattern that corresponds with cluster $C$ personality disorders traits. Also, our results agreed with Faustino Lopez et al. (1999) [18] who stated that the severity of epilepsy is associated with decreased psychosocial well-being and increased psychopathology as epilepsy is a disabling disorder that have a higher feeling of decreased control and perception of being stigmatized and finally low self-esteem [19]. And this was also agreed with Swinkels (2004) [16] who concluded from his study that patients with epilepsy have raised scores for a number of personality disorder traits. Those who are suffering from repeated epileptic seizures have disturbances in the development of personality characteristics, which could explain the relationship between the development of personality disorder traits with the severity and duration of the epilepsy.

Also agreed with Wang X, et al. (2018) [20] who used Eysenck Personality Questionnaire on epileptic patients and showed that patients with epilepsy were presented with significant cognitive impairment and particular personality traits, and epileptic seizure-related factors including earlier age of onset, longer duration of epileptic history, and high seizure frequency were significantly associated with the observed defects in cognition and personality traits.

Bazarnik A. (2018) [21] also agreed with us and concluded that many patients with epilepsy report numerous complaints about worsening of their emotional, cognitive, and social functioning so he emphasized that when evaluating diverse psychological variables such as personality traits. It is possible to draw some conclusions about the inclination of patients with epilepsy to develop specific mental disorders.

Regarding intelligence quotient (IQ), this study showed significant statistical difference in the performance of the controlled epileptic patients with mean of 92.38 and $\mathrm{SD} \pm 4.12$ over the refractory epileptic patients with mean of 90.16 and $\mathrm{SD} \pm 4.4$ and the control group with mean of 91.6 and $\mathrm{SD} \pm 4.3$. This means that the performance of the controlled epileptic group (with the better seizure control) is almost close to the control group, meaning that the severity of epilepsy affects the IQ performance scale of the cases. 
Refractory epileptic verbal means 80.67 with SD \pm 4.94, but without significant statistical difference. Lastly, the deterioration index was higher in controlled epileptic patients with a mean of 8.33 with $\mathrm{SD} \pm 9.55$; while in refractory epileptic group, it was 8.29 with $\mathrm{SD} \pm 7.09$, and in control group was 8.16 with $\mathrm{SD} \pm 8.78$ with no significant differences.

This was agreed with Wang X, et al. (2018) [20] who used the Wechsler Adult Intelligence Scale-Chinese revised and found that patients with epilepsy were presented with significant cognitive impairment. Also, Jacoby et al. (1994) [22] reported that 18\% of epileptics were classified as mentally handicapped.

\section{Conclusion}

Based on the results of this study, we can conclude that patients with epilepsy have raised scores for several personality traits.

We found that patients with epilepsy exhibit more personality traits compared with a control group from the general population.

Also, we found a relationship exists between personality traits and the severity of epilepsy. When patients have more severe epilepsy, they often have a high seizure frequency, and they use more antiepileptic medications. It is likely that in these patients the need for control is usually high; therefore, they are more prone to develop an affected behavior pattern.

\section{Study limitations}

The role of other confounding factors such as the type and dosage of antiepileptic used, the type of epileptic seizures, the cause, and localization of the epileptic activity should be assessed individually in larger scale study.

Factors such as dull normal intelligence and illiteracy can affect the evaluation of personality traits that may need more attention in further studies.

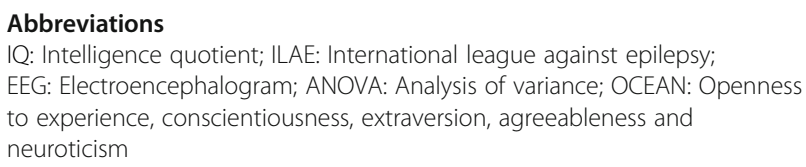

IQ: Intelligence quotient; ILAE: International league against epilepsy; EEG: Electroencephalogram; ANOVA: Analysis of variance; OCEAN: Openness to experience, conscientiousness, extraversion, agreeableness and neuroticism

\section{Acknowledgements}

Not applicable

\section{Authors' contributions}

K. A. M. contributed to study design, interpretation of the data, and preparing and revising the manuscript. Y. M.B. contributed to study design, assessing, interviewing the patients, collecting, and analyzing and interpreting the data. M. F. H. contributed to study design, assessing, interviewing the patients, collecting, and analyzing and interpreting the data. R. H. G. contributed to study design, interpretation of the data, and preparing and revising the manuscript. Also, he is the corresponding author. All authors have read and approved the manuscript and ensure that this is the case.

\section{Funding}

The current study was not supported by any national or international institution or organization.

\section{Availability of data and materials}

The data sets generated and/or analyzed during the current study are available from the corresponding author on reasonable request.

\section{Declarations}

\section{Ethics approval and consent to participate}

The protocol and study design were approved by local ethical committee in faculty of medicine, Assiut University, Egypt (reference number is not available). An informed signed consent was obtained from all participants.

\section{Consent for publication}

All participants' consent for publication were obtained.

\section{Competing interests}

The authors declare that they have no competing interests.

Received: 14 December 2020 Accepted: 6 April 2021

Published online: 01 June 2021

\section{References}

1. Swinkels WAM, Kuyk J, de Graaf EH, van Dyck R, Spinhoven P (2001) Prevalence of psychopathology in Dutch epilepsy inpatients a comparative study. Epilepsy Behav 2:441-447

2. Trimble MR (1988) Personality Disorders and Epilepsy. In: Brihaye J, Calliauw L, Loew F, van den Bergh R (eds) Personality and Neurosurgery: Proceedings of the Third Convention of the Academia Eurasiana Neurochirurgica Brussels, August 30-September 2, 1987. Springer Vienna, Vienna, pp 98-101. https://doi.org/10.1007/978-3-7091-9005-0_20

3. Gibbs FA, Stamps FW. Epilepsy handbook: Thomas; 1958.

4. Trimble M. (2013) Treatment issues for personality disorders in epilepsy,Epilepsia. 54 (suppl.1): 41-45. https://doi.org/10.1111/epi.12104.

5. Fisher RS, Acevedo C, Arzimanoglou A, Bogacz A, Cross JH, Elger CE, Engel J Jr, Forsgren L, French JA, Glynn M, Hesdorffer DC, Lee BI, Mathern GW, Moshé SL, Perucca E, Scheffer IE, Tomson T, Watanabe M, Wiebe S (2014) ILAE official report: a practical clinical definition of epilepsy. Epilepsia 55(4): 475-482. https://doi.org/10.1111/epi.12550

6. Kwan P, Arzimanoglou A, Berg AT, Brodie MJ, Allen Hauser W, Mathern G, Moshé SL, Perucca E, Wiebe S, French J (2010) Definition of drug resistant epilepsy: consensus proposal by the ad hoc Task Force of the ILAE Commission on Therapeutic Strategies. Epilepsia 51(6):1069-1077. https:// doi.org/10.1111/j.1528-1167.2009.02397.x

7. Trimble MR, Schmitz B (2011) Antiepileptic drugs and suicide. Cambridge University Press; Neuropsychiatry Epilepsy 143

8. Melika L (1996) Wechsler Adult Intelligence Scale-Arabic Version. El-Nahda Arabic Library

9. Elwan O, Madkour O, Kamal I, Abdallah M (1973) Steroid contraceptives: neuro-psychiatric \& electroencephalographic complications. J Int Med Res 1(6):534-547. https://doi.org/10.1177/030006057300100605

10. Abdelrakeeb AEM, A.E.H ; Wageeh,A.H ; Ibraheem,R.I Psychological assessment of patients with male erectile disorder in Assiut unpublished. 2003.

11. Goldberg LR (1993) The structure of phenotypic personality traits. Am Psychol 48(1):26-34. https://doi.org/10.1037/0003-066X.48.1.26

12. Costa Jr P, McRae R. Revised NEO Personality Inventory (NEO-PI-R) and NEO Five- Facto Inventory (NEO-FFI) professional manual. Odessa, Fl: Psychological Assessment Resources, Inc. Dalgleish, LI (2003). Risk, needs and consequences. Assessments in child care: A comprehensive guide to frameworks and their use. 1992:86-99.

13. Matthews G, Deary IJ, Whiteman MC (2003) Personality traits (2nd ed.) Cambridge University Press. https://doi.org/10.1017/CBO9780511812736

14. Gaitatzis A, Trimble M, Sander JW (2004) The psychiatric comorbidity of epilepsy. Acta Neurol Scand 110(4):207-220. https://doi.org/10.1111/j.16000404.2004.00324.x

15. Tang WK, Lu J, Ungvari GS, Wong KS, Kwan P (2012) Anxiety symptoms in patients with frontal lobe epilepsy versus generalized epilepsy. Seizure 21(6): $457-460$ 
16. Swinkels WA, Duijsens IJ, Spinhoven P (2004) Personality disorder traits in patients with epilepsy. Seizure 12(8):587-594

17. Swinkels WAM, Duijsens IJ, Spinhoven PH (2003) Personality disorder traits in patients with epilepsy. Seizure 12:587-594

18. Lopez-Rodriguez F, Altshuler L, Kay J, Delarhim S, Mendez M, Engel J Jr

(1999) Personality disorders among medically refractory epileptic patients. J Neuropsychiatry Clin Neurosci 11(4):464-469. https://doi.org/10.1176/ jnp.11.4.464

19. Bear D, Levin K, Blumer D, Chetham D, Ryder J (1982) Interictal behaviour in hospitalized temporal lobe epileptics: relationship to idiopathic psychiatric syndromes. J Neurol Neurosurg Psychiatry 45(6):481-488. https://doi.org/1 0.1136/jnnp.45.6.481

20. Wang X, LV Y, Zhang W, Meng H (2018) Cognitive impairment and personality traits in epilepsy: characterization and risk factor analysis. J Nerv Ment Dis 206(10):794-799. https://doi.org/10.1097/NMD.0000000000000880

21. Bazarnik A (2018) Emotion dysregulation and psychopathology in epilepsy. Pol Merkur Lekarski 44(264):302-307

22. Jacoby A (1992) Epilepsy and the quality of everyday life. Findings from a study of people with well controlled epilepsy. Soc Sci Med 34(6):657-666

\section{Publisher's Note}

Springer Nature remains neutral with regard to jurisdictional claims in published maps and institutional affiliations.

\section{Submit your manuscript to a SpringerOpen ${ }^{\circ}$ journal and benefit from:}

- Convenient online submission

- Rigorous peer review

- Open access: articles freely available online

- High visibility within the field

- Retaining the copyright to your article

Submit your next manuscript at $\boldsymbol{\wedge}$ springeropen.com 